Boise State University

ScholarWorks

Raptor Research Center Publications and

Presentations

Raptor Research Center

3-1-2017

First Record of Nestling Relocation by Adult Gyrfalcons (Falco rusticolus) Following Nest Collapse

Bryce W. Robinson

Boise State University

Neil Paprocki

Peregrine Fund

David L. Anderson

Peregrine Fund

Marc J. Bechard

Boise State University 


\title{
First Record of Nestling Relocation by Adult Gyrfalcons (Falco rusticolus) Following Nest Collapse
}

\author{
Bryce W. Robinson, ${ }^{1,4}$ Neil Paprocki, ${ }^{2,3}$ David L. Anderson, ${ }^{2}$ and Marc J. Bechard ${ }^{1}$
}

\begin{abstract}
Nest collapse has been documented in many bird species, with little discussion of adult behavior following collapse. We present evidence of a partial collapse of a Gyrfalcon (Falco rusticolus) nest during the nestling period and the subsequent adult response. A nest camera captured the nest collapse and showed one adult Gyrfalcon holding a live nestling in its beak before leaving the nest. Later, we found the surviving nestling alive in an alternate nest $5 \mathrm{~m}$ from the original nest, presumably transported there by the adult. We believe this is the first report of an adult Gyrfalcon moving a nestling to a new location following nest disturbance. We place this observation into a context of Gyrfalcon nesting behavior described in published sources. The continued use of nest cameras may provide additional documentation and insight into this behavior and its prevalence in birds. Received 23 September 2015. Accepted 5 June 2016.
\end{abstract}

Key words: Alaska, behavioral response, Falco rusticolus, Gyrfalcon, nest camera, nest collapse, nestling relocation.

Avian nests are susceptible to a wide range of environmental factors that can affect breeding behaviors and nest success (Ricklefs 1969, Dunning and Watts 1991, Penteriani et al. 2002, Bonter et al. 2014). In species that construct nests in trees or on cliffs, extreme weather and nest age can compromise the integrity of the nest, causing complete or partial nest collapse (Grieco 1999, Martínez et al. 2013). Nest collapse is a regular occurrence in birds and has been documented in many families such as the Accipitridae (Reese 1977, Margalida et al. 2007, Watts and Byrd 2007), Ardeidae (Olmos and Silva e Silva 2002), Corvidae (Allan and Davies 2005), Emberizidae

\footnotetext{
${ }^{1}$ Raptor Research Center at Boise State University, 1910 University Drive, Boise, ID, USA.

2 The Peregrine Fund, 5668 W Flying Hawk Lane, Boise, ID, USA.

${ }^{3}$ HawkWatch International, 2240 S 900 E, Salt Lake City, UT, USA.

${ }^{4}$ Corresponding author; email: bryce@ornithologi.com; brycerobinson@u.boisestate.edu
}

(Antonov et al. 2008), Falconidae (Strasser and Heath 2013), Phalacrocoracidae (Minias and Kaczmarek 2013), and Threskiornithidae (Olmos and Silva e Silva 2001). Nest collapse often results in nest failure (Swem 1996), especially during the incubation period (Snyder et al. 1989). Nestlings, however, can survive falls from nests and live to fledging age (Cade 1960, Curnutt and Robertson 1994, Base et al. 2007). Many diurnal raptor species construct, maintain, or occupy stick nests (Newton 1979), and nest collapse and the subsequent provisioning of fallen nestlings appears to be a regular, but infrequent occurrence (Cade 1960, Curnutt and Robertson 1994, Base et al. 2007). Adult behaviors in response to a partial or complete nest collapse are poorly understood, likely due to a general lack of direct observation during or immediately following an incident. In one instance of partial nest collapse in the Redtailed Hawk (Buteo jamaicensis), nestlings that fell and nestlings that remained in the nest were both provisioned and survived to fledging age (M. Kochert, pers. comm.). In other occurrences of nest collapse, adults constructed new stick nests around the location of the fallen nestling(s) (Swem 1996, Base et al. 2007).

Across their circumpolar range, Gyrfalcons (Falco rusticolus) regularly utilize stick nests built by other species (Cade 1960, White and Cade 1971, Barichello 1983, Poole and Bromley 1988, Nielsen and Cade 1990). Cases of nest collapse have been observed in nesting Gyrfalcons, but no information is available on adult response following a collapse event apart from adults provisioning fallen nestlings that survived (Cade 1960, Tömmeraas 2012). We document adult response to the partial collapse of a stick nest occupied by Gyrfalcons in western Alaska in which the female actively transported a live nestling from the partially collapsed nest to an alternate stick nest nearby. To our knowledge, this is the first reported instance in which an adult Gyrfalcon actively transported a nestling from the original nest to an 
alternate nest and provisioned the nestling subsequent to the move.

\section{METHODS}

Study Area.-In the summer of 2014, The Peregrine Fund, Boise State University, and Alaska Department of Fish and Game began a cooperative, long-term research program to investigate the status of nesting Gyrfalcons on the Seward Peninsula in western Alaska. The study area consists of $14,150 \mathrm{~km}^{2}$ of the Seward Peninsula, described by Bente (2011). The landscape is Arctic tundra dominated by low-lying vegetation in coastal and highland areas, and dense willow (Salix spp.) and alder (Alnus spp.) thickets along riparian corridors. Topography consists of rolling tundra interspersed with mountainous terrain, numerous rock outcroppings, and clifflined river systems. The study area provides abundant nesting habitat for Gyrfalcons, with an annual mean of 35 (range: 31 to 39) occupied breeding territories between 2005 and 2010 (Bente 2011).

Camera Installation.-We identified occupied nests by road, foot, and aerial surveys. We installed a Reconyx PC800 (RECONYX, Holmen, WI, USA) motion-activated camera (hereafter referred to as 'nest camera') at each of 10 occupied Gyrfalcon nests to monitor prey deliveries during the nestling period. Nest camera motion activation was programmed at high sensitivity to take three rapid photographs followed by a 15-sec sleep period, and one motion independent time-lapse photograph recurring every $15 \mathrm{~min}$. All nest camera photographs were automatically timestamped with the local, Alaska Daylight Time (AKDT). On 18 May 2014, we installed a camera in a nest which forms the basis of our observations. The nest contained four eggs and was built either by Rough-legged Hawk (Buteo lagopus) or Common Raven (Corvus corax), based on stick size and nest diameter, and was at least 1 year old in 2014.

\section{OBSERVATIONS}

Field Observations.-Photographs from the nest camera confirmed that hatch occurred on 30 May 2014. We conducted routine nest observations for the next week with a Zeiss Victory
DiaScope 65 T* FL (Carl Zeiss AG, Oberkochen, Germany) spotting scope from a distance of ca. 2.4 $\mathrm{km}$ to assess parental presence and behavior at the nest. On 5 June, we began to observe anomalies in adult behavior that led us to suspect failure of the nest. We observed an adult Gyrfalcon perched on the nest cliff, but no adults were seen on the nest during a 4-hr observation period. We began a subsequent nest observation on 9 June from the same location and were able to discern movement of a single Gyrfalcon nestling on a ledge separate from the original occupied nest location. Shortly thereafter, an adult Gyrfalcon landed on the ledge and began brooding the nestling. On 9 June, we entered the nest to determine its fate and retrieve or relocate the nest camera as needed. The condition of the nest confirmed a partial nest collapse. The nest body had slumped considerably, with much of the nest substrate gone and only large sticks remaining (Fig. 1D). One dead nestling, approximately 1 day old, lay on the edge of the nest rim. From the original nest, we observed one live nestling, aged 10 days, $2 \mathrm{~m}$ below and $5 \mathrm{~m}$ south on a grass ledge that appeared to be an old stick nest in poor condition. We then reinstalled the nest camera at the second nest to continue monitoring prey deliveries.

Camera Observations.-On 30 May, at least three eggs had hatched successfully (Fig. 1B). We were unable to assess the fate of the fourth egg from nest camera photographs. Nest camera photos document the loss of the nest's structural integrity from 30 May to 1 June (Fig. 1A-D). The nest collapse was a gradual shifting downward and away from the cliff face, after which the female brooded closer to the cliff-side.

At 04:08 AKDT on 1 June, the nest camera photos show the female making sudden and abrupt movements with wings raised and attention focused on the nest bowl. It appears as if a sudden event happened at this time, such as the nest bowl partially collapsing beneath the brooding female. Subsequent photos show the female making attempts to shift her position in relation to the nest. At 04:10 the female is seen standing on the rim of the nest holding a nestling in her bill (Fig. 2 ), suggesting the approximate time that she actively transported a living nestling from the partially collapsed nest to a separate nest location. We can discern in the original photo (Fig. 2) that the nestling in the adult's beak has its wings 


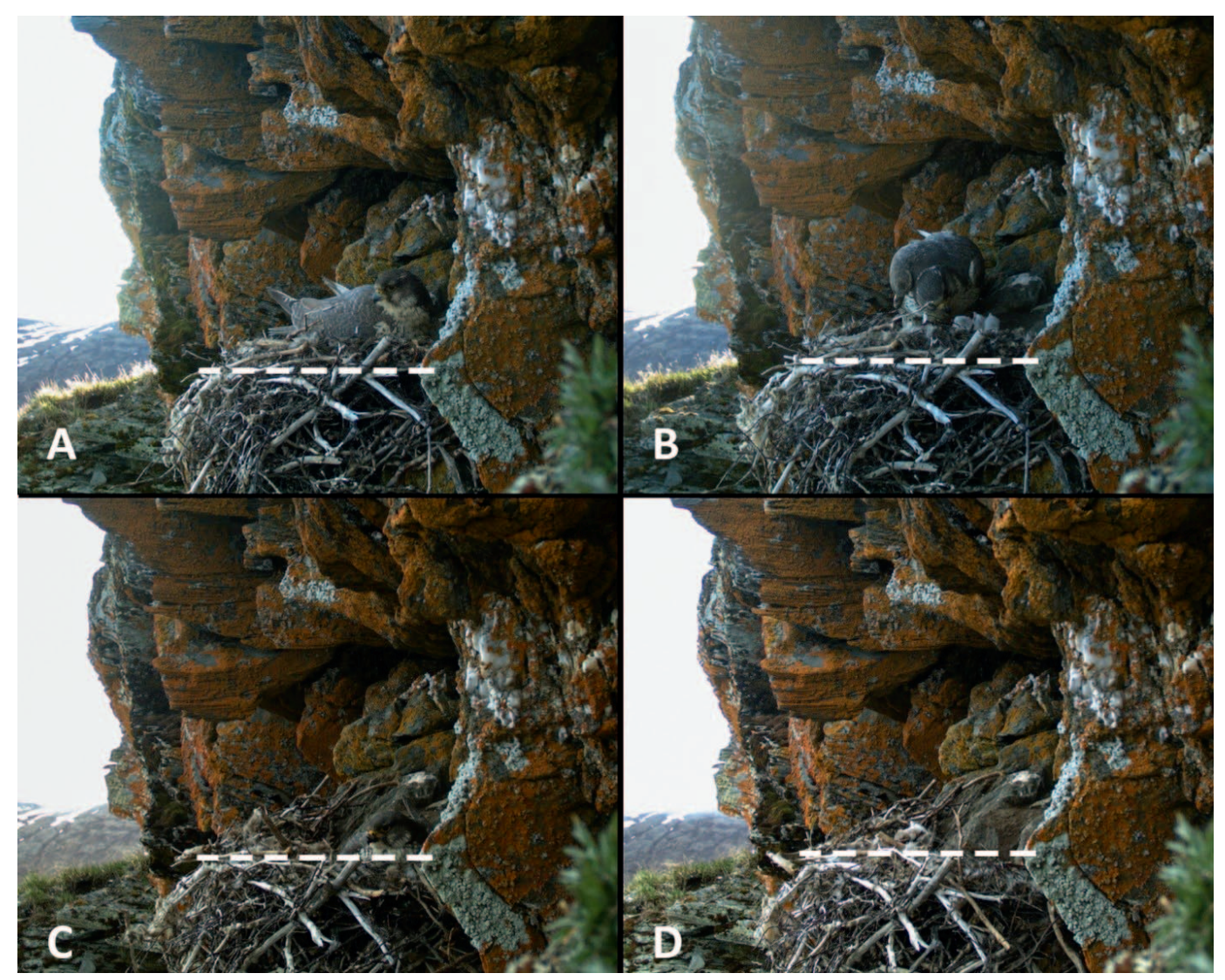

FIG. 1A-D. Four photos illustrating the displacement of the Gyrfalcon (Falco rusticolus) nest preceding (A-C) and following (D) the partial nest collapse. The white dashed line serves as a reference to illustrate the distance the nest shifted through time. (A). 29 May 2014: The brooding female sits above the dashed line. (B). 30 May 2014: The female feeding 3 nestlings, all of which sit above the dashed line. (C). 31 May 2014: The brooding female the day prior to the nest collapse event. The dashed line aligns with her breast, showing substantial movement of the nest structure. (D). 1 June 2014: After the partial nest collapse event and the relocation of the living nestling to an alternate nest location.

outstretched, its head held upright, and its eyes open, indicating that it was indeed alive.

The adults made several visits to the original nest site after the removal of the live nestling. An adult reappeared at the nest at 04:15 to continue brooding until 05:15 when the adult left and a dead nestling could clearly be seen on the rim of the old nest. The nest remained empty until 12:15 when an adult bird was present in the nest again and appeared to brood the dead nestling until 12:45 when it moved to a perch just above the nest. The dead nestling was no longer visible at this time as it was presumably in the nest bowl, which was later confirmed during the 9 June nest entry. After this time, no adult Gyrfalcon made an attempt to brood in the collapsed nest. However, we observed four additional visits to the nest by adults on 1,2, 4, and 5 June. Apart from the single dead nestling in the nest, we found no evidence of un-hatched eggs, eggshells, or other dead nestlings near the original nest site.

Images from the relocated nest camera indicated that the adults abandoned the alternate nest after the nest entry on 9 June, resulting in the death of the surviving nestling. The adults avoided the nest site for over $24 \mathrm{hrs}$ following our nest entry, leaving the nestling exposed and unfed. The nestling appeared alert and vocal at the time of nest entry, even making efforts to avoid us during camera installation (BWR, NP, DLA, MB, pers. obs.) without this final disturbance, the nestling may have survived to fledge. 


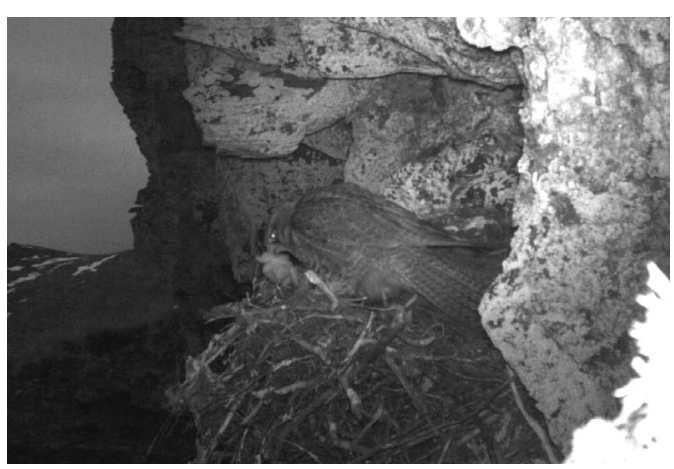

FIG. 2. Photo taken 1 June 2014 at 04:10 AKDT by a Reconyx PC 800 motion-activated camera. The photo shows a Gyrfalcon (Falco rusticolus) nestling held in the adult's beak. This illustrates the moment the adult moved the nestling to a new location following partial nest collapse. The location of the new nest site is outside the view of the camera.

\section{DISCUSSION}

Nest collapse is a regular occurrence in bird species that build stick nests, but detailed descriptions of adult response to nest collapse are practically non-existent. Lack of detailed information on adult response could arise if the typical response is simply nest abandonment or if nest monitoring methods are incapable of recording specific behaviors of adults. In the current study, our use of nest cameras allowed us to document what may be the first reported incident of an adult bird actively transporting a live nestling following the partial collapse of the nest.

Nest collapse has been documented across the circumpolar Gyrfalcon range and seems to be an uncommon but regular occurrence. In Alaska, events include the collapse of old Rough-legged Hawk nests, but any mention of adult behaviors following collapse are lacking in these instances (Cade 1960). Remains of stick nests and dead young or eggs have been found on the ground, but in multiple cases nestlings have survived the fall and were provisioned on the ground (T. Booms, pers. comm.). In Norway, cases of nest collapse have been documented without mention of adult behaviors (Tömmeraas 2012). But in some cases information regarding nest collapse was documented: two cases during the incubation period (A. Östlyngen, pers. comm.), and five cases for c. 100 breeding attempts in which two nests with eggs and three with chicks all failed subsequently (L. E.
Furuseth, pers. comm.). In Iceland, three of 378 nesting attempts in raven stick nests collapsed during incubation (two cases) and the nestling period (one case). Eggs perished but two nestlings (the complete brood) survived the fall and were cared for by parents on the talus below. In another case, nestlings that remained in the nest were fed, but the fallen nestling was ignored and died (Ó. K. Nielsen, pers. comm.).

Adult behavior following events similar to nest collapse are worth noting. The most common response to dead nestlings is for adults to carry nestlings away from the nest, indicated by camera monitoring in our study. Gyrfalcon nestlings that die are sometimes eaten by or fed to siblings, but adults have been documented carrying a pipping egg, a small nestling, and three dead c. 20-day-old nestlings away from the nest to discard the carcasses (longest distance c. $250 \mathrm{~m}$; Ó. K. Nielsen, pers. comm.).

The most similar observation to ours regarding the response of an adult Gyrfalcon to threats to a nestling or nest contents is a report from Iceland that describes an encounter in which an incubating female was flushed by four human observers. After the Gyrfalcon left the nest, a Great Black-backed Gull (Larus marinus) took an egg, was then attacked by the female Gyrfalcon, and dropped the egg. The falcon managed to grab the egg in midair in one foot and return it to the nest (Guðmundsson 1945).

Although we present evidence that an adult Gyrfalcon transported a nestling to an alternate nest, we did not see the adult fly to the alternate nest and deposit the nestling. Therefore, we must rule out other possible explanations for the relocation of the nestling, namely that the nestling moved independently to the new location or that it coincidentally fell into the alternate nest from the original nest. The age of the nestling at the time of the nest collapse, the terrain around the nests, and the positions of the nests relative to each other allow us to discount these alternative explanations. First, the nestling age was 2 days at the time of the nest collapse, and 11 days at the time of our reentry. Altricial Gyrfalcon young at this early age lack motor and physical abilities that would be required to traverse a vertical cliff and talus slope to the alternate nest. Second, because of the distance between the nests we can discount the hypothesis that the nestling fell from one nest to 
the other. We therefore conclude from photographic evidence that an adult Gyrfalcon relocated a 2day-old nestling from a collapsing nest to an alternate nest nearby.

Adult behavior following the nest collapse and relocation of the nestling is worth noting. Although the only living nestling was relocated to an alternate nest, the adults remained at the original nest for some time after the nest collapse. Following the death of nestlings, adult Gyrfalcons will attempt to feed and brood dead nestlings (BWR, pers obs.). Adults showed this behavior at the partially collapsed nest, as they made multiple visits following the nest collapse event to either brood the remaining dead nestling, or maintain a presence at the nest. The adults' reproductive instincts and resulting attachment to the nest may have caused this behavior, as it appears to have taken several days for a cessation of visits to the original nest, even though they may have been attending a surviving offspring at a separate location.

We believe that our observation is the first substantiated case of an adult Gyrfalcons actively relocating its nestling from its original nest to an alternate nest. Given the regularity of nest collapse in some species of birds, similar adult response to collapse may be more common than previously recognized. Careful monitoring will allow us to determine if the present observation is a rare case, or an example of an important behavior that has not been documented previously.

\section{ACKNOWLEDGMENTS}

We are indebted to J. Earthman for his help with field logistics and support. We thank T. L. Booms and P. Bente for their wisdom and help with this research. C. M. Davis helped prepare figures for the manuscript. O. Nielsen provided many helpful comments that greatly improved the manuscript. All field methods involving live raptors were approved in the Boise State IACUC protocol \#006-AC14004 and conducted under federal and state permits. The Alaska Department of Fish and Game provided additional logistical support. The Peregrine Fund and The Raptor Research Center at Boise State University provided funding for this research.

\section{LITERATURE CITED}

Allan, D. G. And G. B. Davies. 2005. Breeding biology of House Crows (Corvus splendens) in Durban, South Africa. Ostrich 76:21-31.
Antonov, A., B. G. Stokke, A. Moksnes, and E. Røskaft. 2008. Unusually high losses to nest collapse in Blackheaded Buntings Emberiza melanocephala nesting on a preferred plant species. Bird Study 55:233-235.

Barichello, N. 1983. Selection of nest sites by Gyrfalcons (Falco rusticolus). Thesis. University of British Columbia, Vancouver, Canada.

Base, D. L., S. Zender, and J. W. Watson. 2007. Golden Eagles (Aquila chrysaetos) build new nest below cliff and provision fallen nestling. Journal of Raptor Research 41:76-77.

Bente, P. J. 2011. Abundance and multi-year occupancy of Gyrfalcons Falco rusticolus on the Seward Peninsula, Alaska. Pages 295-306 in Gyrfalcons and ptarmigan in a changing world. Volume 1 (R. T. Watson, T. J. Cade, M. Fuller, G. Hunt, and E. Potapov, Editors). The Peregrine Fund, Boise, Idaho, USA.

Bonter, D. N., S. A. Maclean, S. S. Shah, and M. C. MogLia. 2014. Storm-induced shifts in optimal nesting sites: a potential effect of climate change. Journal of Ornithology 155:631-638.

CAdE, T. J. 1960. Ecology of the Peregrine and Gyrfalcon populations in Alaska. University of California Publications in Zoölogy 63:151-290.

Curnutt, J. L. and W. B. Robertson JR. 1994. Bald Eagle nest site characteristics in south Florida. Journal of Wildlife Management 58:218-221.

DunNing JR., J. B. AND B. D. WatTs. 1991. Habitat occupancy by Bachman's Sparrow in the Francis Marion National Forest before and after Hurricane Hugo. Auk 108:723-725.

Grieco, F. 1999. Nest-site limitations and colony development in tree-nesting Great Cormorants. Waterbirds 22:417-423.

GuĐmundsson, B. 1945. Skammgóður vermir. Náttúrufræðingurinn 15:186.

Margalida, A., L. M. González, R. Sánchez, J. Oria, L. Prada, J. Caldera, A. Aranda, and J. I. Molina. 2007. A long-term large-scale study of the breeding biology of the Spanish Imperial Eagle (Aquila adalberti). Journal of Ornithology 148:309-322.

Martínez, J. E., M. V. JimÉnez-Franco, I. Zuberogoitia, M. LeÓn-Ortega, and J. F. Calvo. 2013. Assessing the short-term effects of an extreme storm on Mediterranean forest raptors. Acta Oecologica 48:47-53.

Minias, P. AND K. KaczmareK. 2013. Is it always beneficial to breed in the centre? Trade-offs in nest site selection within the colony of a tree-nesting waterbird. Journal of Ornithology 154:945-953.

Newton, I. 1979. Population ecology of raptors. T. and A. D. Poyser Ltd., London, United Kingdom.

Nielsen, Ó. K. and T. J. Cade. 1990. Annual cycle of the Gyrfalcon in Iceland. National Geographic Research 6:41-62.

Olmos, F. and R. Silva E Silva. 2001. Breeding biology and nest site characteristics of the Scarlet Ibis in southeastern Brazil. Waterbirds 24:58-67.

Olmos, F. And R. Silva e Silva. 2002. Breeding biology of the Little Blue Heron (Egretta caerulea) in southeastern Brazil. Ornitología Neotropical 13:17-30. 
Penteriani, V., M. Mathiaut, and G. Boisson. 2002. Immediate species responses to catastrophic natural disturbances: windthrow effects on density, productivity, nesting stand choice, and fidelity in Northern Goshawks (Accipiter gentilis). Auk 119:1132-1137.

Poole, K. G. and R. G. Bromley. 1988. Natural history of the Gyrfalcon in the central Canadian Arctic. Arctic 41:31-38.

Reese, J. G. 1977. Reproductive success of Ospreys in central Chesapeake Bay. Auk 94:202-221.

RickLEFs, R. E. 1969. An analysis of nesting mortality in birds. Smithsonian Contributions to Zoology 9:1-48.

Snyder, N. F. R., S. R. Beissinger, and R. E. Chandler. 1989. Reproduction and demography of the Florida Everglade (Snail) Kite. Condor 91:300-316.
Strasser, E. H. and J. A. Heath. 2013. Reproductive failure of a human-tolerant species, the American Kestrel, is associated with stress and human disturbance. Journal of Applied Ecology 50:912-919.

Swem, T. R. 1996. Aspects of the breeding biology of Rough-legged Hawks along the Colville River, Alaska. Thesis. Boise State University, Boise, Idaho, USA.

TömmeraAs, P. J. 2012. The Gyrfalcon's Falco rusticolus nest site - myths and reality. Våre Rovdyr 26:18-37.

Watts, B. D. And M. A. Byrd. 2007. Impact of Hurricane Isabel on Bald Eagle nests and reproductive performance in the lower Chesapeake Bay. Condor 109:206209.

White, C. M. and T. J. CAde. 1971. Cliff-nesting raptors and ravens along the Colville River in arctic Alaska. Living Bird 10:107-150. 